
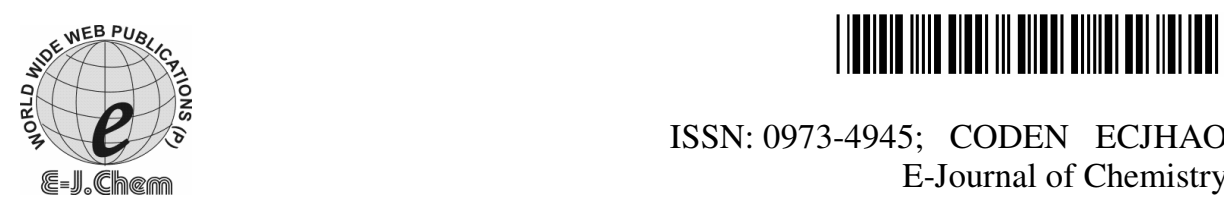

ISSN: 0973-4945; CODEN ECJHAO E-Journal of Chemistry

http://www.e-journals.net 2008, 5(S2), 1103-1113

\title{
3D QSAR Studies of DAMNI Analogs as Possible Non-nucleoside Reverse Transcriptase Inhibitors
}

\author{
S. GANGULY* and V.GOPALAKRISHNAN \\ Department of Pharmaceutical Sciences, \\ Birla Institute of Technology, Mesra, Ranchi-835215, Jharkhand. \\ swastikaganguly@bitmesra.ac.in
}

Received 27 January 2008; Accepted 20 March 2008

\begin{abstract}
The non-nucleoside inhibitors of HIV-1-reverse transcriptase (NNRTIs) are an important class of drugs employed in antiviral therapy. Recently, a novel family of NNRTIs commonly referred to as 1-[2diarylmethoxy] ethyl) 2-methyl-5-nitroimidazoles (DAMNI) derivatives have been discovered. The 3D-QSAR studies on DAMNI derivatives as NNRTIs was performed by comparative molecular field analysis (CoMFA) and comparative molecular similarity indices analysis (CoMSIA) methods to determine the factors required for the activity of these compounds. The global minimum energy conformer of the template molecule 15 , the most active molecule of the series, was obtained by simulated annealing method and used to build the structures of the molecules in the dataset. The combination of steric and electrostatic fields in CoMSIA gave the best results with cross-validated and conventional correlation coefficients of 0.654 and 0.928 respectively. The predictive ability of CoMFA and CoMSIA were determined using a test set of ten DAMNI derivatives giving predictive correlation coefficients of 0.92 and 0.98 respectively indicating good predictive power. Further, the robustness of the models was verified by bootstrapping analysis. The information obtained from CoMFA and CoMSIA 3D contour maps may be of utility in the design of more potent DAMNI analogs as NNRTIs in future.
\end{abstract}

Keywords: 2-Methyl-5-Nitroimidazole, 3D QSAR, DAMNI analogs, CoMFA, CoMSIA

\section{Introduction}

The reverse transcriptase (RT) of the Human Immunodeficiency Virus is a key target in the treatment of Acquired Immune Deficiency Syndrome (AIDS) for which no completely successful, chemotherapy is yet available ${ }^{1}$.There are two classes of HIV-1-RT inhibitors, the nucleoside (NRTIs) (e.g., AZT, 3TC, ddI, ddC) and the non-nucleosideinhibitors (NNRTIs) depending on their mechanism of action. NRTIs act on the catalytic site of the reverse 
transcriptase enzyme, preventing DNA synthesis, whereas NNRTIs bind noncompetitively to a hydrophobic site close to the catalytic site, forcing the enzyme to adopt an inactive conformation $^{2}$. The advantage of NNRTIs over NRTIs is that they are relatively less cytotoxic and more selective than NRTIs. However, the real advantage is abolished by a broad cross resistance by most of the NNRTIs.To date only three non-nucleosideRT inhibitors have been approved for clinical use namely nevirapine, delaviridine and efavirenz . Several NNRTIs (MKC442, Troviridine, S-1153/ AG1549 PNU142721, ACT, and HBY1293/GW420867X) are currently undergoing clinical trials. Other examples of NNRTIs include TIBO compounds ${ }^{3}$, HEPT derivatives ${ }^{4}$, BHAP analogs ${ }^{5}$, 2-pyridinones ${ }^{6}$ and PETT compounds ${ }^{7}$. Recently 1-[2-(diarylmethoxy)-ethyl] 2-mehyl-5-nitroimidazoles (DAMNIs), a novel family of NNRTIs active at submicromolar concentration has been discovered ${ }^{8-10}$.

Comparative molecular field analysis (CoMFA) and Comparative molecular similarity indices analysis (CoMSIA) are powerful and versatile tools to build and design an activity model (QSAR) for a given set of molecules in rational drug design and related applications ${ }^{11}$.CoMFA methodology is based on the assumption that the changes in the biological activity correlate with the changes in the steric and electrostatic fields of the molecules. The CoMSIA ${ }^{12,13}$ method differs by the way the molecular fields are calculated and by including additional molecular fields, such as lipophilic and hydrogen bond potential. The additional fields in CoMSIA provide better visualization and interpretation of the obtained correlation in terms of field contribution to the activity of the compound. On the basis of CoMFA and CoMSIA models for DAMNI derivatives, we attempted to elucidate a structure activity relationship to provide useful information for the design and synthesis of more potent DAMNI analogs and related derivatives with predetermined affinities.

\section{Experimental}

\section{Dataset for analysis}

Reported data on a series of 40 DAMNI analogs ${ }^{8-10}$ were used (Table 1). The $\mathrm{EC}_{50}$ data were used for QSAR analysis as a dependent parameter after converting reciprocal of the logarithm of $\mathrm{EC}_{50}\left(\mathrm{pEC}_{50}\right)$ values. $\mathrm{EC}_{50}$ is the micromolar concentration of the compounds required to achieve $50 \%$ protection of MT-4 cells from HIV-1 induced cytopathogenicity, as determined by MTT method. The total set of DAMNI analogs (40 compounds) was divided into the training set (30 compounds) and test set (10 compounds) (Figure 1).The ratio of training set molecules to test set molecules was in the approximate ratio 4:1.Test and training set compounds were chosen manually such that low, moderate, and high activity compounds were present approximately in equal proportions in both sets.

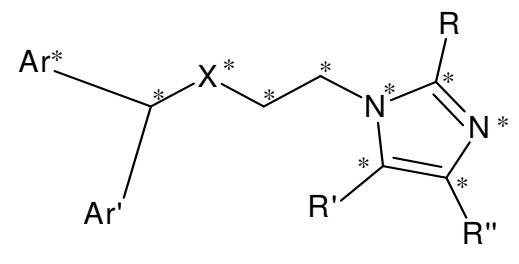

1-40

Figure1. Novel DAMNI analogs used for 3D QSAR studies.

Common substructure is labeled with*. 
Table 1. Dataset used for 3D-QSAR analyses

\begin{tabular}{|c|c|c|c|c|c|c|c|}
\hline \multirow{2}{*}{$\begin{array}{c}\text { Compd. } \\
\text { No. }\end{array}$} & \multicolumn{6}{|c|}{ Substituents } & \multirow{2}{*}{$\mathrm{EC}_{50}$} \\
\hline & $\mathrm{Ar}$ & $\mathrm{Ar}^{\prime}$ & $X$ & $\mathrm{R}$ & $\mathrm{R}^{\prime}$ & $\mathrm{R}^{\prime \prime}$ & \\
\hline 1 & $\mathrm{C}_{6} \mathrm{H}_{5}$ & $\mathrm{C}_{6} \mathrm{H}_{5}$ & $\mathrm{O}$ & $\mathrm{H}$ & $\mathrm{H}$ & $\mathrm{H}$ & 100 \\
\hline 2 & $\mathrm{C}_{6} \mathrm{H}_{5}$ & $2,4-\mathrm{Cl}-\mathrm{C}_{6} \mathrm{H}_{3}$ & $\mathrm{O}$ & $\mathrm{H}$ & $\mathrm{H}$ & $\mathrm{H}$ & 31 \\
\hline 3 & $\mathrm{C}_{6} \mathrm{H}_{5}$ & $4-\mathrm{C}_{6} \mathrm{H}_{5}-\mathrm{C}_{6} \mathrm{H}_{4}$ & $\mathrm{O}$ & $\mathrm{CH}_{3}$ & $\mathrm{NO}_{2}$ & $\mathrm{H}$ & 17 \\
\hline 4 & $\mathrm{C}_{6} \mathrm{H}_{5}$ & $\mathrm{H}$ & $\mathrm{O}$ & $\mathrm{CH}_{3}$ & $\mathrm{H}$ & $\mathrm{NO}_{2}$ & 22 \\
\hline 5 & $\mathrm{C}_{6} \mathrm{H}_{5}$ & $\mathrm{C}_{6} \mathrm{H}_{5}$ & $\mathrm{O}$ & $\mathrm{CH}_{3}$ & $\mathrm{NO}_{2}$ & $\mathrm{H}$ & 0.20 \\
\hline 6 & $\mathrm{C}_{6} \mathrm{H}_{5}$ & 4-tertbutyl-C6 64 & $\mathrm{O}$ & $\mathrm{CH}_{3}$ & $\mathrm{NO}_{2}$ & $\mathrm{H}$ & 4 \\
\hline 7 & $\mathrm{C}_{6} \mathrm{H}_{5}$ & $4-\mathrm{F}-\mathrm{C}_{6} \mathrm{H}_{4}$ & $\mathrm{O}$ & $\mathrm{CH}_{3}$ & $\mathrm{NO}_{2}$ & $\mathrm{H}$ & 0.9 \\
\hline 8 & 2,4-Cl- $\mathrm{C}_{6} \mathrm{H}_{3}$ & $\mathrm{C}_{6} \mathrm{H}_{5}$ & $\mathrm{O}$ & $\mathrm{CH}_{3}$ & $\mathrm{NO}_{2}$ & $\mathrm{H}$ & 1.5 \\
\hline 9 & 2- $\mathrm{CH}_{3}-\mathrm{C}_{6} \mathrm{H}_{4}$ & $\mathrm{C}_{6} \mathrm{H}_{5}$ & $\mathrm{O}$ & $\mathrm{CH}_{3}$ & $\mathrm{NO}_{2}$ & $\mathrm{H}$ & 0.2 \\
\hline 10 & $2-\mathrm{F}-\mathrm{C}_{6} \mathrm{H}_{4}$ & $\mathrm{C}_{6} \mathrm{H}_{5}$ & $\mathrm{O}$ & $\mathrm{CH}_{3}$ & $\mathrm{NO}_{2}$ & $\mathrm{H}$ & 0.2 \\
\hline 11 & $3-\mathrm{CH}_{3}-\mathrm{C}_{6} \mathrm{H}_{4}$ & $\mathrm{C}_{6} \mathrm{H}_{5}$ & $\mathrm{O}$ & $\mathrm{CH}_{3}$ & $\mathrm{NO}_{2}$ & $\mathrm{H}$ & 0.1 \\
\hline 12 & $3-\mathrm{F}-\mathrm{C}_{6} \mathrm{H}_{4}$ & $\mathrm{C}_{6} \mathrm{H}_{5}$ & $\mathrm{O}$ & $\mathrm{CH}_{3}$ & $\mathrm{NO}_{2}$ & $\mathrm{H}$ & 5 \\
\hline 13 & $\mathrm{C}_{6} \mathrm{H}_{5}$ & $\mathrm{C}_{6} \mathrm{H}_{11}$ & $\mathrm{O}$ & $\mathrm{CH}_{3}$ & $\mathrm{NO}_{2}$ & $\mathrm{H}$ & 0.3 \\
\hline 14 & $\mathrm{C}_{6} \mathrm{H}_{5}$ & $\mathrm{H}$ & $\mathrm{O}$ & $\mathrm{CH}_{3}$ & $\mathrm{NO}_{2}$ & $\mathrm{H}$ & 4.2 \\
\hline 15 & $\mathrm{C}_{6} \mathrm{H}_{5}$ & Thiophenyl & $\mathrm{O}$ & $\mathrm{CH}_{3}$ & $\mathrm{NO}_{2}$ & $\mathrm{H}$ & 0.03 \\
\hline 16 & $4-\mathrm{CH}_{3}-\mathrm{C}_{6} \mathrm{H}_{4}$ & Thiophenyl & $\mathrm{O}$ & $\mathrm{CH}_{3}$ & $\mathrm{NO}_{2}$ & $\mathrm{H}$ & 0.3 \\
\hline 17 & $3-\mathrm{F}-\mathrm{C}_{6} \mathrm{H}_{4}$ & Thiophenyl & $\mathrm{O}$ & $\mathrm{CH}_{3}$ & $\mathrm{NO}_{2}$ & $\mathrm{H}$ & 0.14 \\
\hline 18 & $3-\mathrm{Cl}-\mathrm{C}_{6} \mathrm{H}_{4}$ & Thiophenyl & $\mathrm{O}$ & $\mathrm{CH}_{3}$ & $\mathrm{NO}_{2}$ & $\mathrm{H}$ & 0.08 \\
\hline 19 & $2-\mathrm{F}_{-} \mathrm{C}_{6} \mathrm{H}_{4}$ & Thiophenyl & $\mathrm{O}$ & $\mathrm{CH}_{3}$ & $\mathrm{NO}_{2}$ & $\mathrm{H}$ & 0.12 \\
\hline 20 & 2,3-F-C $6 \mathrm{H}_{4}$ & Thiophenyl & $\mathrm{O}$ & $\mathrm{CH}_{3}$ & $\mathrm{NO}_{2}$ & $\mathrm{H}$ & 0.06 \\
\hline 21 & $\mathrm{C}_{6} \mathrm{H}_{5}$ & 3-Cl-2-Thiophenyl & $\mathrm{O}$ & $\mathrm{CH}_{3}$ & $\mathrm{NO}_{2}$ & $\mathrm{H}$ & 1.2 \\
\hline 22 & $\mathrm{C}_{6} \mathrm{H}_{5}$ & Furyl & $\mathrm{O}$ & $\mathrm{CH}_{3}$ & $\mathrm{NO}_{2}$ & $\mathrm{H}$ & 0.1 \\
\hline 23 & $\mathrm{C}_{6} \mathrm{H}_{5}$ & Pyrimidinyl & $\mathrm{O}$ & $\mathrm{CH}_{3}$ & $\mathrm{NO}_{2}$ & $\mathrm{H}$ & 0.08 \\
\hline 24 & $4-\mathrm{OCH}_{3}-\mathrm{C}_{6} \mathrm{H}_{4}$ & $\mathrm{C}_{6} \mathrm{H}_{5}$ & $\mathrm{O}$ & $\mathrm{CH}_{3}$ & $\mathrm{NO}_{2}$ & $\mathrm{H}$ & 86 \\
\hline 25 & $\mathrm{C}_{6} \mathrm{H}_{5}$ & $\mathrm{C}_{6} \mathrm{H}_{5}$ & $\mathrm{O}$ & $\mathrm{CH}_{3}$ & $\mathrm{H}$ & $\mathrm{NO}_{2}$ & 67 \\
\hline 26 & $\mathrm{C}_{6} \mathrm{H}_{5}$ & $\mathrm{C}_{6} \mathrm{H}_{5}$ & $\mathrm{O}$ & $\mathrm{H}$ & $\mathrm{H}$ & $\mathrm{NO}_{2}$ & 78 \\
\hline 27 & 2,4-Cl-C6 $6 \mathrm{H}_{4}$ & $4-\mathrm{Cl}-\mathrm{C}_{6} \mathrm{H}_{4}$ & $\mathrm{O}$ & $\mathrm{H}$ & $\mathrm{H}$ & $\mathrm{H}$ & $>26$ \\
\hline 28 & $\mathrm{C}_{6} \mathrm{H}_{5}$ & $4-\mathrm{Cl}-\mathrm{C}_{6} \mathrm{H}_{4}$ & $\mathrm{O}$ & $\mathrm{CH}_{3}$ & $\mathrm{NO}_{2}$ & $\mathrm{H}$ & 12.5 \\
\hline 29 & $\mathrm{C}_{6} \mathrm{H}_{5}$ & $\mathrm{C}_{6} \mathrm{H}_{5}$ & $\mathrm{NH}$ & $\mathrm{CH}_{3}$ & $\mathrm{NO}_{2}$ & $\mathrm{H}$ & 12 \\
\hline 30 & $2-\mathrm{CH}_{3}-\mathrm{C}_{6} \mathrm{H}_{4}$ & Thiophenyl & $\mathrm{O}$ & $\mathrm{CH}_{3}$ & $\mathrm{NO}_{2}$ & $\mathrm{H}$ & 0.45 \\
\hline $31^{\mathrm{a}}$ & 5-(1,3 butadiene) $\mathrm{C}_{6} \mathrm{H}_{4}$ & $\mathrm{C}_{6} \mathrm{H}_{5}$ & $\mathrm{O}$ & $\mathrm{CH}_{3}$ & $\mathrm{NO}_{2}$ & $\mathrm{H}$ & 106 \\
\hline $32^{\mathrm{a}}$ & $\mathrm{C}_{6} \mathrm{H}_{5}$ & $\mathrm{H}$ & $\mathrm{N}-\mathrm{CH}_{2} \mathrm{C}_{6} \mathrm{H}_{5}$ & $\mathrm{CH}_{3}$ & $\mathrm{NO}_{2}$ & $\mathrm{H}$ & 84 \\
\hline $33^{\mathrm{a}}$ & $\mathrm{C}_{6} \mathrm{H}_{5}$ & $\mathrm{C}_{6} \mathrm{H}_{5}$ & $\mathrm{O}$ & $\mathrm{H}$ & $\mathrm{NO}_{2}$ & $\mathrm{H}$ & $>100$ \\
\hline $34^{\mathrm{a}}$ & $3,5-\mathrm{Cl}-\mathrm{C}_{6} \mathrm{H}_{3}$ & $\mathrm{C}_{6} \mathrm{H}_{5}$ & $\mathrm{O}$ & $\mathrm{CH}_{3}$ & $\mathrm{NO}_{2}$ & $\mathrm{H}$ & 45 \\
\hline $35^{\mathrm{a}}$ & 2-Cl- $\mathrm{C}_{6} \mathrm{H}_{4}$ & $\mathrm{C}_{6} \mathrm{H}_{5}$ & S & $\mathrm{CH}_{3}$ & $\mathrm{NO}_{2}$ & $\mathrm{H}$ & 12 \\
\hline $36^{\mathrm{a}}$ & $2-\mathrm{F}-\mathrm{C}_{6} \mathrm{H}_{4}$ & $\mathrm{C}_{6} \mathrm{H}_{5}$ & $\mathrm{NH}$ & $\mathrm{CH}_{3}$ & $\mathrm{NO}_{2}$ & $\mathrm{H}$ & 50 \\
\hline $37^{\mathrm{a}}$ & $4-\mathrm{CH}_{3}-\mathrm{C}_{6} \mathrm{H}_{4}$ & $\mathrm{C}_{6} \mathrm{H}_{5}$ & $\mathrm{NH}$ & $\mathrm{CH}_{3}$ & $\mathrm{NO}_{2}$ & $\mathrm{H}$ & 44 \\
\hline $38^{\mathrm{a}}$ & $3-\mathrm{Cl}-\mathrm{C}_{6} \mathrm{H}_{4}$ & $\mathrm{C}_{6} \mathrm{H}_{5}$ & $\mathrm{~S}$ & $\mathrm{CH}_{3}$ & $\mathrm{NO}_{2}$ & $\mathrm{H}$ & 64 \\
\hline $39^{\mathrm{a}}$ & $\mathrm{C}_{6} \mathrm{H}_{5}$ & $\mathrm{H}$ & $S$ & $\mathrm{CH}_{3}$ & $\mathrm{NO}_{2}$ & $\mathrm{H}$ & 60 \\
\hline $40^{\mathrm{a}}$ & $4-\mathrm{Cl}-\mathrm{C}_{6} \mathrm{H}_{4}$ & Thiophenyl & $\mathrm{O}$ & $\mathrm{CH}_{3}$ & $\mathrm{NO}_{2}$ & $\mathrm{H}$ & 57.5 \\
\hline
\end{tabular}

Test set compounds 


\section{Molecular modelling}

The 3D-QSAR was performed ${ }^{14}$ using SYBYL 7.1 installed on a Dell computer with Red Hat Linux Enterprise Version 3.0.The initial conformation of the most active analog 15 was obtained from simulated annealing as it enables the rapid identification of the global minimum energy conformer ${ }^{15}$. The system was subjected to simulated annealing by heating at $1000 \mathrm{~K}$ for $1 \mathrm{ps}$ and then cooling at $200 \mathrm{~K}$ for $1 \mathrm{ps}$. The exponential annealing function was used and 10 such cycles were run. The least energy conformer obtained by this method was subjected to further minimization. The minimized conformer, thus obtained, was taken as the template and rest of the molecules were built from it. A constrained minimization followed by full minimization was carried out on these molecules in order to prevent the conformations moving to a false region. Tripos force field and partial atomic charges calculated by the GasteigerHuckel method were used. Powell's conjugate gradient method was used for minimization. The gradient of $0.05 \mathrm{kcal} \mathrm{mol}^{-1} \mathrm{~A}^{\circ-1}$ was set as a convergence criterion.

\section{Alignment}

The most crucial input for CoMFA is the alignment of the molecules. The template molecule 15 was taken and the rest of the molecules were aligned to it using the DATABASE ALIGNMENT method in the SYBYL. The molecules were aligned to the template molecule by using common substructure labeled with* in 1(Figure 1). The aligned molecules are shown in Figure 2.

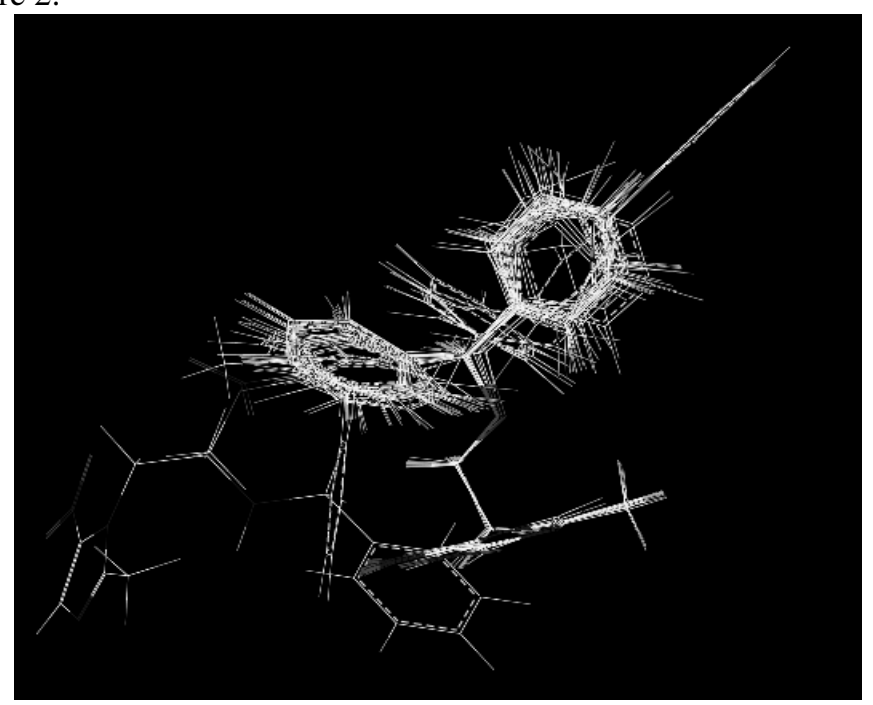

Figure 2. Alignment of the training set molecules.

\section{CoMFA interaction energy calculation ${ }^{12}$}

The steric and electrostatic CoMFA fields were calculated at each lattice intersection of a regularly spaced grid of $2.0 \mathrm{~A}^{\circ}$ in all three dimensions within defined region. The van der Waals potential and coulombic terms representing the steric and electrostatic fields respectively were calculated using standard tripos force fields. A distance dependent dielectric constant of 1.00 was used. An $s p 3$ carbon atom with +1.00 charge was used as a probe atom. The steric and electrostatic fields were truncated at $+30.00 \mathrm{kcal} \mathrm{mol}^{-1}$, and the electrostatic fields were ignored at the lattice points with maximal steric interactions. 


\section{CoMSIA interaction energy calculation ${ }^{12}$}

The steric, electrostatic, hydrophobic, hydrogen bond donor and hydrogen bond acceptor potential fields were calculated at each lattice intersection of a regularly spaced grid of $2.0 \mathrm{~A}^{\circ}$. A probe atom with radius $1.0 \mathrm{~A}^{\circ}$ and +1.0 charge with hydrophobicity of +1.0 and hydrogen bond donor and hydrogen bond acceptor properties of +1.0 was used to calculate steric, electrostatic, hydrophobic, donor and acceptor fields. The contribution from these descriptors was truncated at $0.3 \mathrm{kcal} \mathrm{mol}^{-1}$.

Partial least square (PLS) analysis ${ }^{12}$

PLS method was used to linearly correlate the CoMFA fields to the inhibitory activity values. The cross-validation ${ }^{16,17}$ analysis was performed using the leave one out (LOO) method in which one compound is removed from the dataset and its activity is predicted using the model derived from the rest of the dataset. The cross-validated $r^{2}$ that resulted in optimum number of components and lowest standard error of prediction were considered for further analysis. Equal weights were assigned to steric and electrostatic fields using COMFA_STD scaling option. To speed up the analysis and reduce noise, a minimum filter value $\sigma$ of $2.00 \mathrm{kcal} \mathrm{mol}^{-1}$ was used. Final analysis was performed to calculate conventional $\mathrm{r}^{2}$ using the optimum number of components. To further assess the robustness and statistical confidence of the derived models, bootstrapping analysis for 100 runs was performed. Bootstrapping involves the generation of many new data sets from original data set and is obtained by randomly choosing samples from the original data set. The statistical calculation is performed on each of these bootstrapping samplings. The difference between the parameters calculated from the original data set and the average of the parameters calculated from the many bootstrapping samplings is a measure of the bias of the original calculations. The entire cross-validated results were analysed considering the fact that a value of $r_{\mathrm{cv}}^{2}$ above 0.3 indicates that probability of chance correlation ${ }^{12}$ is less than $5 \%$.

\section{Predictive correlation coefficient ${ }^{12}$}

The predictive ability of each 3D-QSAR model was determined from a set of ten compounds that were not included in the training set. These molecules were aligned, and their activities were predicted. The predictive correlation coefficient $\left(\mathrm{r}_{\text {pred }}^{2}\right)$, based on molecules of test set, is defined as,

$$
\mathrm{r}_{\text {pred }}^{2}=(\mathrm{SD}-\mathrm{PRESS}) / \mathrm{SD}
$$

where SD is the sum of the squared deviations between the biological activities of the test set and mean activities of the training set molecules and PRESS is the sum of squared deviation between predicted and actual activity values for every molecule in test set.

\section{Results and Discussion}

The CoMFA model obtained with 30 DAMNI derivatives in training set resulted in a sixcomponent model with cross-validated correlation coefficient of 0.697 and minimum standard error. This analysis was used for final non-cross validated run, giving a correlation coefficient of 0.925 giving a good linear correlation between the observed and predicted activities of the molecules in the training set. To test the predictive ability of the resulting model, a test set of ten molecules excluded from the model creation work was used. The predictive correlation coefficient of 0.924 was obtained for CoMFA model. A high $\mathrm{r}^{2}$ value of 0.739 during 100 runs of bootstrapped ${ }^{18,19}$ analysis further supports the statistical validity of the model. The results of PLS analysis for CoMFA and CoMSIA are shown in Table 2. The alignment of the training set molecules is shown in Figure 2. The relative contributions 
of steric and electrostatic fields for CoMFA are in the ratio 6:3. Steric interactions of molecule with active site of the enzyme could be an important factor for NNRT inhibitory activity. A plot of predicted (CoMFA) versus actual activity for training set molecules is shown in Figure 3.

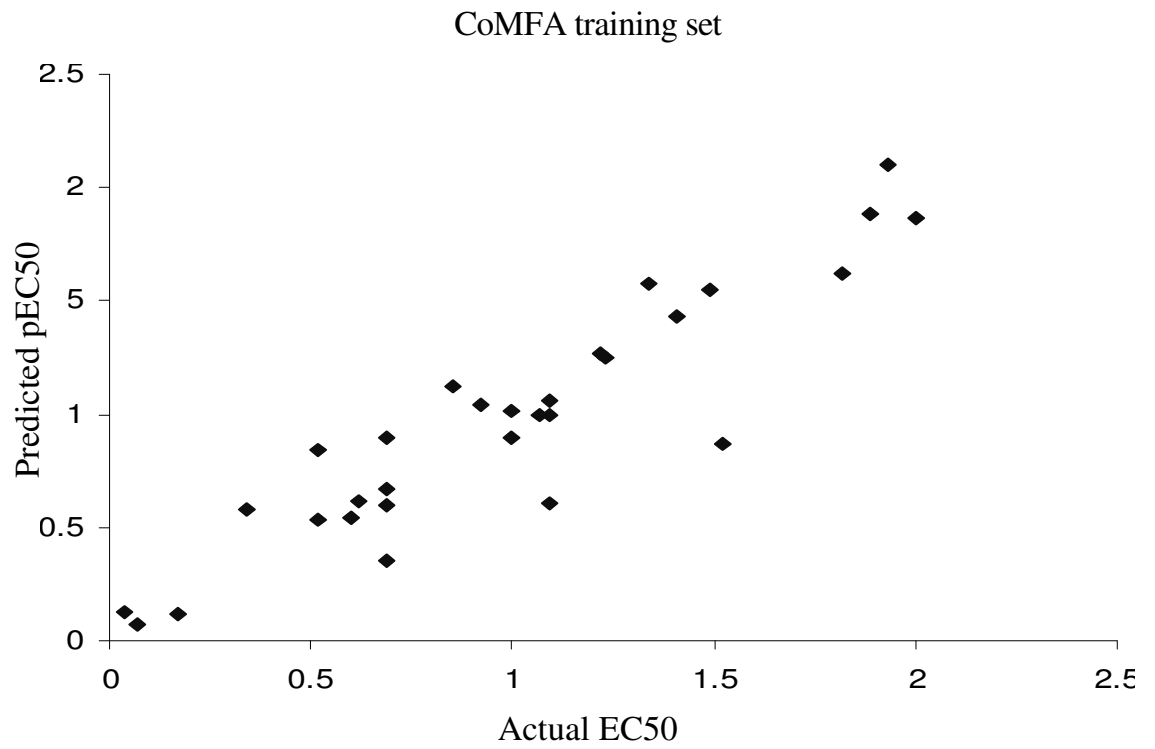

Figure 3. Plot of predicted versus actual $\mathrm{EC}_{50}$ values of training set molecules for CoMFA model.

CoMSIA training set

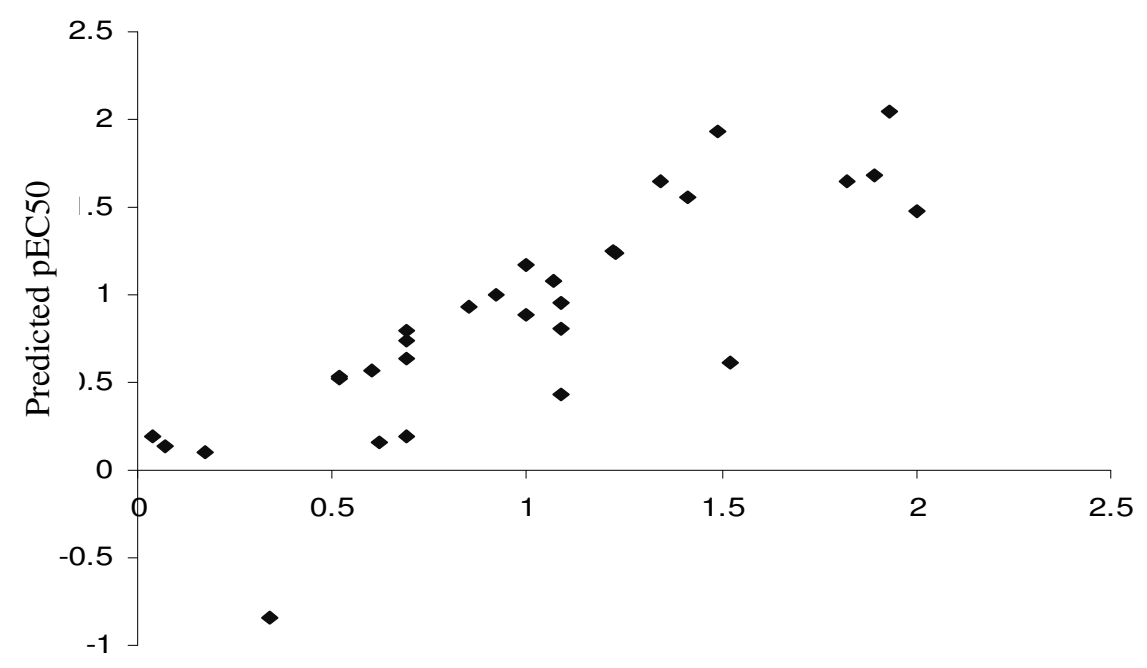

Actual pEC50

Figure 4. Plot of predicted versus actual $\mathrm{EC}_{50}$ values of training set molecules for CoMSIA model 


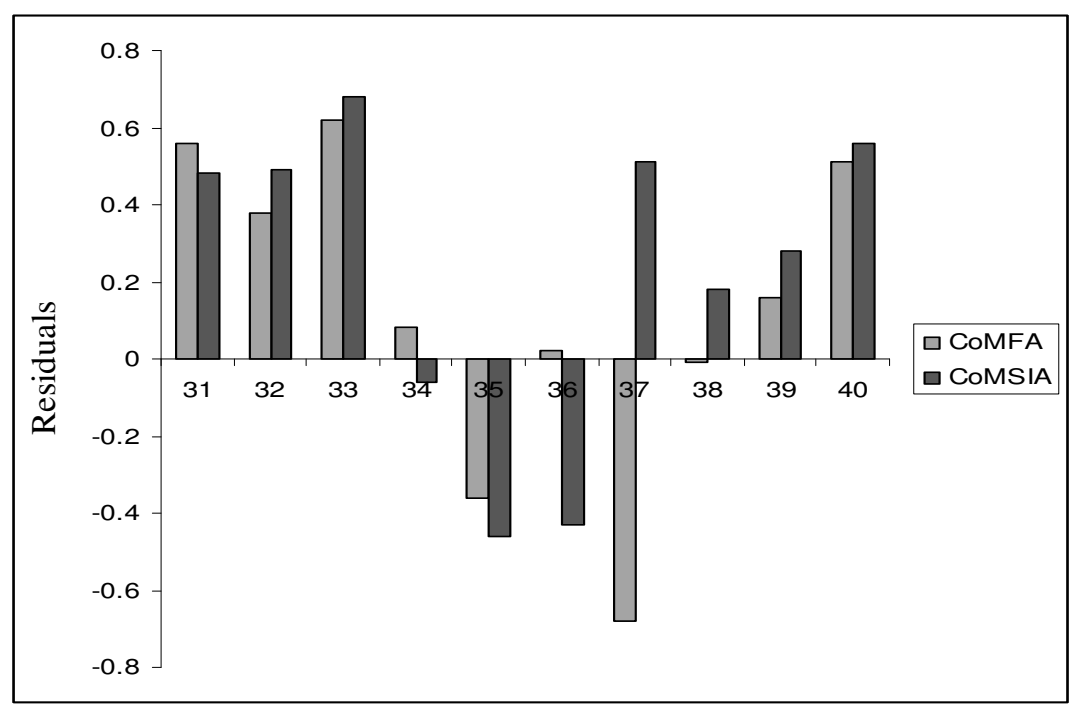

Figure 5. Histogram of test set molecules.

Table 2. Summary of CoMFA and CoMSIA Statistics

\begin{tabular}{ccccc}
\hline \multirow{2}{*}{ Parameters } & \multirow{2}{*}{ CoMFA } & \multicolumn{3}{c}{ CoMSIA } \\
\cline { 3 - 5 } & & SE Model 1 & SEH Model 2 & SEHDA Model 3 \\
\hline $\mathrm{r}_{\mathrm{cv}}^{2}$ & 0.697 & 0.654 & 0.564 & 0.525 \\
$\mathrm{~N}$ & 6 & 6 & 6 & 6 \\
$\mathrm{r}^{2}$ & 0.925 & 0.928 & 0.921 & 0.912 \\
$\mathrm{SEE}$ & 0.150 & 0.340 & 0.356 & 0.375 \\
F-test value & 68.830 & 49.370 & 44.606 & 39.940 \\
PRESS & 1.722 & 2.783 & 4.237 & 1.901 \\
$\mathrm{r}_{\text {pred }}^{2}$ & 0.924 & 0.982 & 0.874 & 0.934 \\
$\mathrm{r}_{\text {bs }}$ & 0.739 & 0.640 & 0.569 & 0.552 \\
SD & 0.012 & 0.019 & 0.021 & 0.020 \\
& & Contributions, \% & & \\
Steric & 0.351 & 0.262 & 0.223 & 0.351 \\
Electrostatic & 0.649 & 0.428 & 0.405 & 0.649 \\
Hydrophobic & & & 0.311 & 0.245 \\
Acceptor & & & & 0.019 \\
Donor & & & & 0.108 \\
\hline
\end{tabular}

$\mathrm{r}_{\mathrm{cv}}^{2}=$ cross-validated correlation coefficient; $\mathrm{N}=$ number of components; $\mathrm{r}^{2}=$ conventional correlation coefficient; SEE = standard error of estimate; PRESS= predicted residual sum of squares of test set molecules, $r_{\text {pred }}^{2}=$ predictive correlation coefficient, $\mathrm{r}^{2}{ }_{\mathrm{bs}}=$ correlation coefficient after 100 runs of bootstrapping analysis, $\mathrm{SD}=$ standard deviation from 100 bootstrapping runs, $\mathrm{S}=$ steric field, $\mathrm{E}=$ electrostatic field, $\mathrm{H}=$ hydrophobic field, $\mathrm{D}=$ hydrogen bond donor field, $\mathrm{A}=$ hydrogen bond acceptor field.

Figure 4 represents the plot of predicted (CoMSIA) versus actual activity values, while the test set residuals of CoMFA and CoMSIA analyses are shown in Figure 5. The actual, predicted and residual values of training and test set for CoMFA and CoMSIA are given in 
Tables 3 and 4 respectively. Contour maps were generated as scalar product of coefficients and standard deviation associated with each CoMFA column. The 3D-QSAR contour maps revealing the contribution of CoMFA and CoMSIA fields are shown in Figures. 6 and 7 respectively. The CoMFA steric interactions are represented by green $(\mathrm{G})$ and yellow $(\mathrm{Y})$ coloured contours while electrostatic interactions are represented by red (R) and blue (B) coloured contours. The bulky substituents are favoured in green regions and disfavoured in yellow (Y) regions. The increase in positive charge is favoured in blue (B) regions while the increase in negative charge is favoured in red $(\mathrm{R})$ regions. The most active molecule 15 (template, $\mathrm{EC}_{50} 0.3 \mu \mathrm{M}$ ) is displayed in the background of contours. The electrostatic contours of CoMFA (Figure 6) shows a red contour near the third position of the imidazole nucleus, two red $(\mathrm{R})$ contours near the thienyl ring, A blue contour enclosing the fifth position of imidazole nucleus of the template molecule and a blue contour away from the phenyl ring.

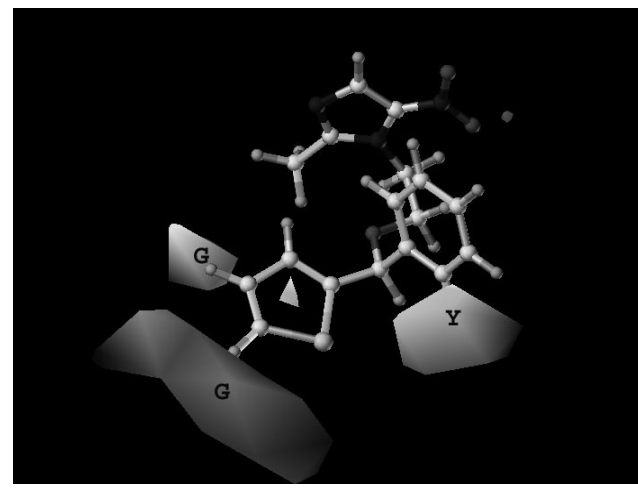

a

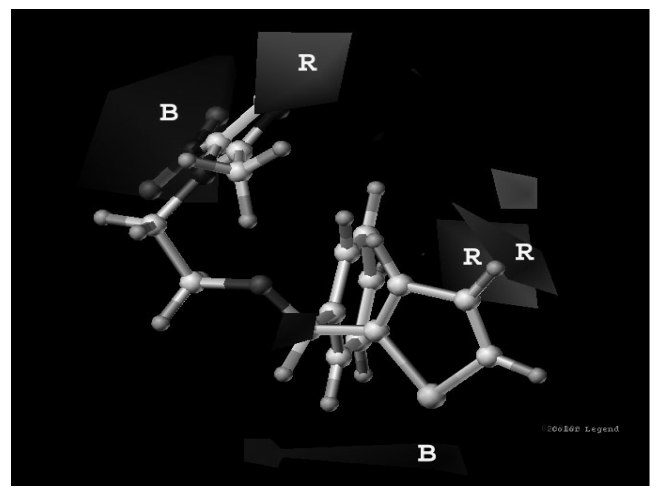

b

Figure 6. The CoMFA steric and (b) electrostatic contour maps. One of the most active molecules 15 is shown in the background. Red (R) colour is a negative charged region, blue (B) a positively charged region,green $(\mathrm{G})$ a positive sterically active region, and yellow (G) a negatively sterically active region.

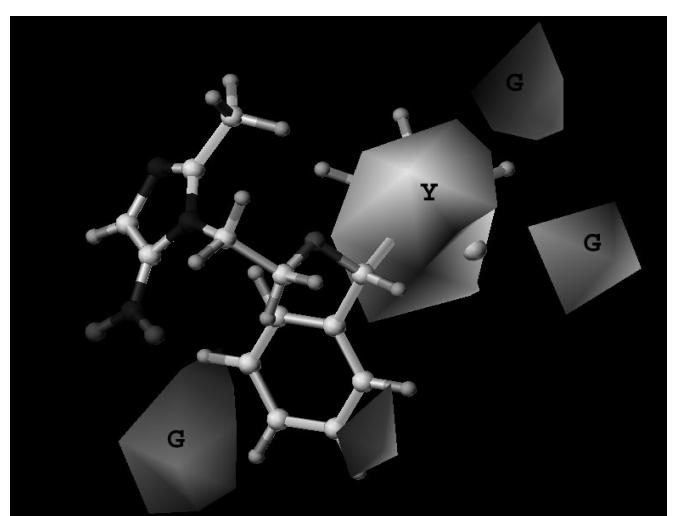

(a)

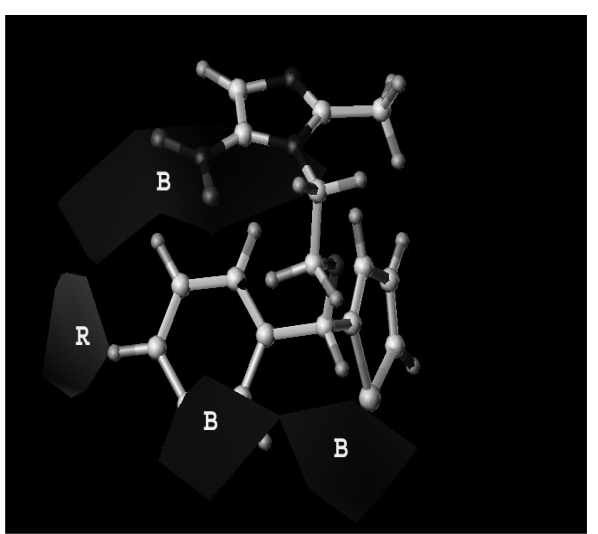

(b)

Figure 7. The CoMSIA steric (a) and electrostatic (b) contour maps. One of the most active molecules 15 is shown in the background. Red $(\mathrm{R})$ colour is a negative charged region, blue (B) a positively charged region, green (G) a positive sterically active region, and yellow (G) a negatively sterically active region. 
Table 3. Experimental and predicted inhibitory activities of compounds in training set

\begin{tabular}{|c|c|c|c|c|c|}
\hline \multirow{2}{*}{ Compd. No } & \multirow{2}{*}{$\mathrm{pEC}_{50}$ Experimental } & \multicolumn{2}{|c|}{$\mathrm{pEC}_{50}$ Predicted } & \multicolumn{2}{|c|}{ Residual activity } \\
\hline & & CoMFA & CoMSIA & CoMFA & CoMSIA \\
\hline 1 & 2.00 & 1.87 & 1.48 & 0.13 & 0.52 \\
\hline 2 & 1.49 & 1.55 & 1.93 & -0.06 & -0.44 \\
\hline 3 & 1.23 & 1.25 & 1.24 & -0.02 & -0.01 \\
\hline 4 & 1.34 & 1.58 & 1.65 & -0.24 & -0.31 \\
\hline 5 & 0.69 & 0.35 & 0.19 & 0.34 & 0.50 \\
\hline 6 & 0.60 & 0.54 & 0.57 & 0.06 & 0.03 \\
\hline 7 & 0.04 & 0.13 & 0.19 & -0.09 & -0.15 \\
\hline 8 & 0.17 & 0.12 & 0.10 & 0.05 & 0.07 \\
\hline 9 & 0.69 & 0.60 & 0.64 & 0.09 & 0.05 \\
\hline 10 & 0.69 & 0.67 & 0.80 & 0.02 & -0.11 \\
\hline 11 & 1.00 & 0.90 & 0.89 & 0.10 & 0.11 \\
\hline 12 & 0.69 & 0.90 & 0.74 & -0.21 & -0.05 \\
\hline 13 & 0.52 & 0.53 & 0.52 & -0.01 & 0.00 \\
\hline 14 & 0.62 & 0.62 & 0.16 & 0.00 & 0.46 \\
\hline 15 & 1.52 & 0.87 & 0.61 & -0.65 & -0.91 \\
\hline 16 & 0.52 & 0.84 & 0.53 & -0.31 & -0.01 \\
\hline 17 & 0.85 & 1.12 & 0.93 & -0.27 & -0.08 \\
\hline 18 & 1.09 & 1.06 & 0.81 & 0.03 & 0.28 \\
\hline 19 & 0.92 & 1.04 & 1.00 & -0.12 & -0.08 \\
\hline 20 & 1.22 & 1.27 & 1.25 & -0.05 & -0.03 \\
\hline 21 & 0.07 & 0.07 & 0.14 & 0.00 & -0.07 \\
\hline 22 & 1.00 & 1.01 & 1.17 & -0.01 & -0.17 \\
\hline 23 & 1.09 & 1.00 & 0.96 & 0.09 & 0.13 \\
\hline 24 & 1.93 & 2.10 & 2.05 & -0.17 & -0.12 \\
\hline 25 & 1.82 & 1.62 & 1.65 & 0.20 & 0.17 \\
\hline 26 & 1.89 & 1.88 & 1.68 & 0.01 & 0.21 \\
\hline 27 & 0.34 & 0.58 & 0.84 & -0.24 & -0.50 \\
\hline 28 & 1.41 & 1.43 & 1.56 & -0.02 & -0.14 \\
\hline 29 & 1.09 & 0.61 & 0.43 & 0.48 & 0.66 \\
\hline 30 & 1.07 & 1.00 & 1.08 & 0.07 & -0.01 \\
\hline
\end{tabular}

Table 4. Experimental and predicted inhibitory activities of compounds in test set

\begin{tabular}{cccccc}
\hline \multirow{2}{*}{ Compd. No. } & Actual $\mathrm{pCC}_{50}$ & \multicolumn{2}{c}{ Predicted $\mathrm{pEC}_{50}$} & \multicolumn{2}{c}{ Residual activity } \\
\cline { 3 - 6 } & & CoMFA & CoMSIA & CoMFA & CoMSIA \\
\hline 31 & 2.02 & 1.46 & 1.54 & 0.56 & 0.48 \\
32 & 1.92 & 1.54 & 1.43 & 0.38 & 0.49 \\
33 & 2.00 & 1.38 & 1.32 & 0.62 & 0.68 \\
34 & 1.65 & 1.57 & 1.71 & 0.08 & -0.06 \\
35 & 1.07 & 1.43 & 1.53 & -0.36 & -0.46 \\
36 & 1.69 & 1.67 & 2.12 & 0.02 & -0.43 \\
37 & 1.64 & 0.96 & 1.13 & -0.68 & 0.51 \\
38 & 1.80 & 1.81 & 1.62 & -0.01 & 0.18 \\
39 & 1.77 & 1.61 & 1.49 & 0.16 & 0.28 \\
40 & 1.76 & 1.25 & 1.20 & 0.51 & 0.56 \\
\hline
\end{tabular}


The red regions near the third position of imidazole ring of template molecule indicates that biological activity can be enhanced by introduction of more electronegative groups at this position for strong electrostatic field interactions. The blue region near the fifth substitution position of imidazole ring suggests that biological activity will be decreased by electronegative group at the above-mentioned position. Two red contours near the thiophene group between suggest that biological activity will be diminished by introduction of electropositive groups at this site. Green contour near fourth and fifth position of thiophene ring indicates that the bulky groups at this position will increase activity. Yellow contour near the sixth position of phenyl ring indicates that bulky substituents at these positions decrease anti-HIV activity. The CoMSIA results were obtained using the same structural alignment and same training and test set as defined in the CoMFA. The combination of steric and electrostatic fields in CoMSIA gave the best results (Model 1), giving cross-validation correlation coefficient of 0.654 , conventional correlation coefficient of 0.928 and predictive correlation coefficient of 0.982 . The other combinations like (i) steric, electrostatic and hydrophobic fields (Model 2) and (ii) all fields (Model 3) in CoMSIA also gave statistically significant models. The other combinations in CoMSIA gave statistically insignificant results (data not shown). The Models 2 and 3 exhibit relatively lower cross-validated, conventional and predictive correlation coefficients compared to model 1 , the best amongst various fields combinations in CoMSIA. The Model 1 of CoMSIA was used for final analysis and predictions. The $\mathrm{r}^{2}$ value of 0.640 during 100 runs of analysis ${ }^{18,19}$ also shows that the Model 1 is stable and statistically robust. The contributions of steric and electrostatic fields of ComSIA are in ratio 6:3 (Table 2).Comparing this with the field contributions of CoMFA analysis, it is revealed that steric and electrostatic interactions could be an important factor for NNRT inhibitory activity. A comparison of the residuals of the models from CoMFA and CoMSIA is made to evaluate their predictive ability (Table 4). Molecule 33 shows high residual value and this may be due to the absence of a methyl group in the second position of the imidazole ring in 33 with respect to the corresponding substituents in other test molecules. Considering the steric contours of CoMSIA (Model 1), green (G) contours indicate favourable regions while yellow (Y) contours indicate unfavourable regions for bulkier substituents. In the electrostatic contours, the introduction of electronegative substituents in red (R) regions may increase the affinity while in blue (B) regions decrease the affinity. The steric contours (Figure 6a and 7a) produced by CoMFA and CoMSIA (Model 1) respectively are quite different. The analysis of steric CoMSIA contours shows presence of a green contour near the third and fourth position of the phenyl ring, a small yellow contour at the fifth position of the phenyl ring and a yellow contour enclosing the thiophene ring. The electrostatic contours (Figure. $6 \mathrm{~b}$ and $7 \mathrm{~b}$ ) produced by CoMFA and CoMSIA are slightly different. The analysis of electrostatic CoMSIA contours shows presence of a small red (R) contour near fourth position of the phenyl ring of the template molecule, a blue (B) contour near the third and fourth position of the phenyl ring and a blue contour near the thiophene ring. The best CoMSIA model (Model 1) indicates that hydrophobic, hydrogen bond donor and hydrogen bond acceptor fields do not improve the model. The CoMFA and CoMSIA models described are predictive enough to guide the design of new molecules.

\section{Conclusions}

The 3D-QSAR analyses, CoMFA and CoMSIA have been applied to a set of DAMNI analogs active against HIV -1 RT .Statistically significant models with good correlative and predictive power for NNRT inhibitory activities of the DAMNI analogs were obtained. The initial geometry of the template molecule (15, the most active of the series) was obtained 
from the simulated annealing approach and was then used to derive remaining structures. The robustness of the derived models was verified by bootstrapping method. The comparison of CoMFA and CoMSIA models reveal that the combination of steric and electrostatic fields in CoMSIA gave the best results. Results of this study may be utilized an important basis for future drug design studies and synthesis of more potent HIV-1 RT inhibitors.

\section{Acknowledgements}

One of the authors G.V. gratefully acknowledges the financial support to this work by UGC in the form of Junior Research Fellowship.

\section{References}

1. Medina Franco J L B, Rodriguez-Morales S, Juarez-Gordiano C, Hernandez-Campos A and Jimenez-Barbero J, Bioorg Med Chem., 2004, 12, 6085.

2. Freitas R F and Galembeck S E, Chem Phys Lett., 2005, 48, 131.

3. Lather V and Madan A K, Bioorg Med Chem., 2005, 13, 3263.

4. Miyasaka T, Tanaka H, Baba M, Hayakawa H, Walker R T, Balazarini J and DeClercq E, J Med Chem., 1989, 32, 2507.

5. Romero D L, Busso M, Tan C, Reusser F, Palmer J R, Poppe S M, Aristoff P A, Downey K M, So A G and Resnick L, Proc Natl Acad Sci., 1991, 88, 8806.

6. Saari W S, Wai J S, Fisher T E, Thomas C M, Hoffman J M, Rooney C S, Smith A M, Jones J H, Bamberger D L, Goldman M E, O'Brien J A, Nunberg J H, Quintero J C, Schleif W A, Emini E A and Anderson P S J, J Med Chem.,1992, 35(21), 3792.

7. Bell F W, Cantrell A S, Hoegberg M, Jaskunas S R, Johansson N G, Jordan C L, Kinnick M D, Lind P and Morin J M Jr. et al, J Med Chem., 1995, 38(25), 4929.

8. Silvestri R, Artico M, Massa S, Marceddu T, Montis F D and Colla P L, Bioorg Med Chem., 2000, 10, 253.

9. Silvestri R, Artico M, Martino G D, Ragno R, Massa S, Loddo R, Murgioni C, Loi A G, La Colla P and Pani A, J Med Chem., 2002, 45, 1567.

10. Martino G D, Regina G L, Pasquali A D, Ragno R, Bergamini A, Ciaprini C, Sinistro A, Maga G, Crespan E, Artico M and Silvetsri R, J Med Chem,. 2005, 48, 4378.

11. Ravichandran V and Agrawal R K, Bioorg \& Med Chem Lett., 2007, 17, 2197.

12. Chakroborti A K, Gopalakrishnan B, Sobhia M E and Malde A K, Eur J Med Chem., 2003, 38, 975.

13. Klebe G, Abraham U and Mietzner T, J Med Chem. 1994, 37(24), 4130.

14. SYBYL Molecular Modelling System, version 7.1; Tripos Associates; St.Louis, MO.

15. Barakat M T and Dean P M, J Comput Aided Mol Des., 1990, 4, 295.

16. Halgren T A, J Am Chem Soc., 1990, 112(12), 4710.

17. Podlogar B L and Ferguson D M, Drug Des Discov., 2000, 17(1), 4.

18. Cramer R D, Bunce J D, Patterson D E and Frank I E, Quantitative Structure-Activity Relationships 1988, 7(1), 18.

19. Murthy V S and Kulkarni V M, Bioorg Med Chem., 2002, 10(7), 2267. 


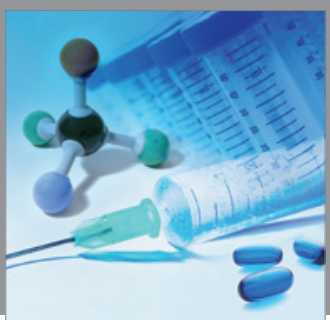

International Journal of

Medicinal Chemistry

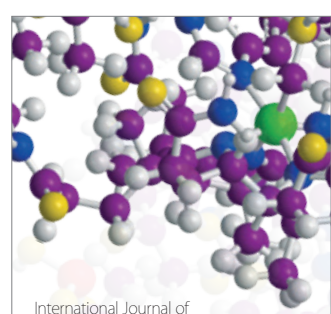

Carbohydrate Chemistry

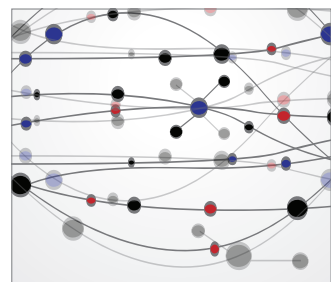

The Scientific World Journal
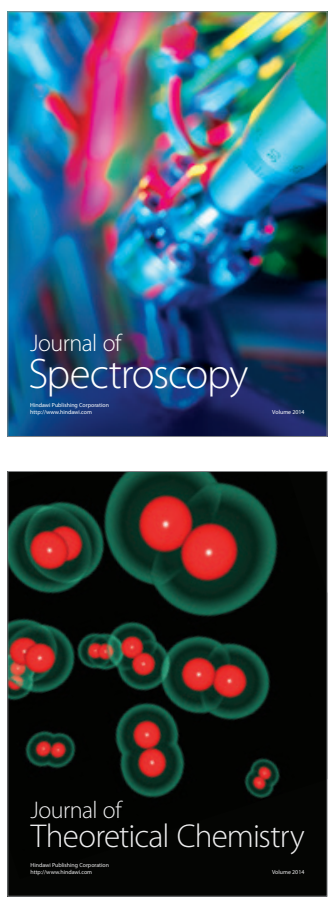
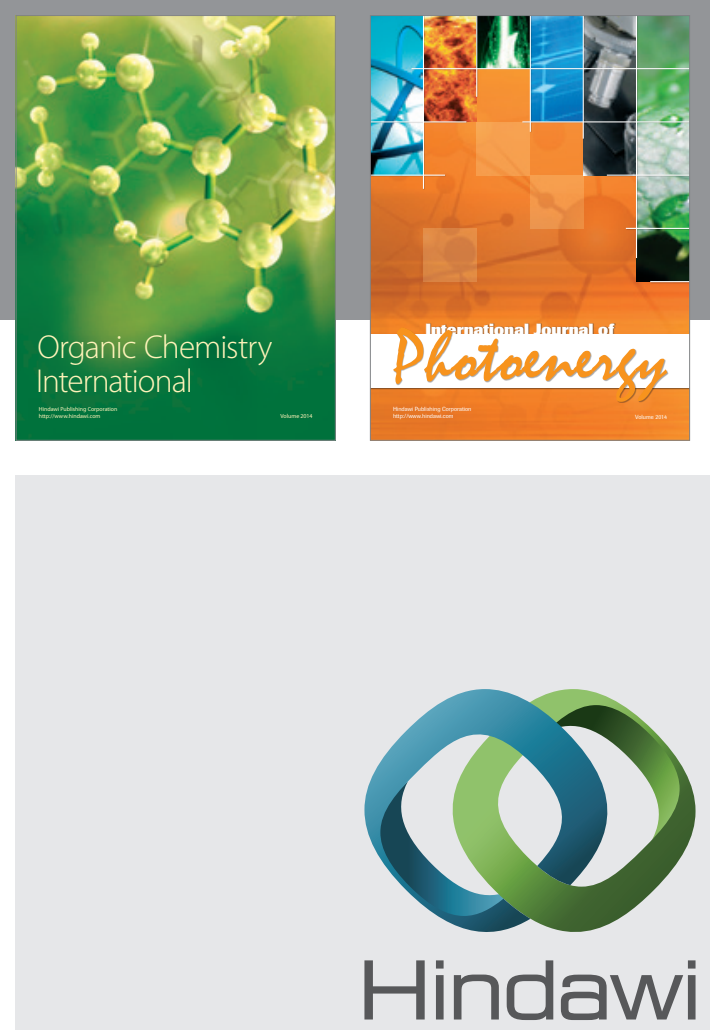

Submit your manuscripts at

http://www.hindawi.com
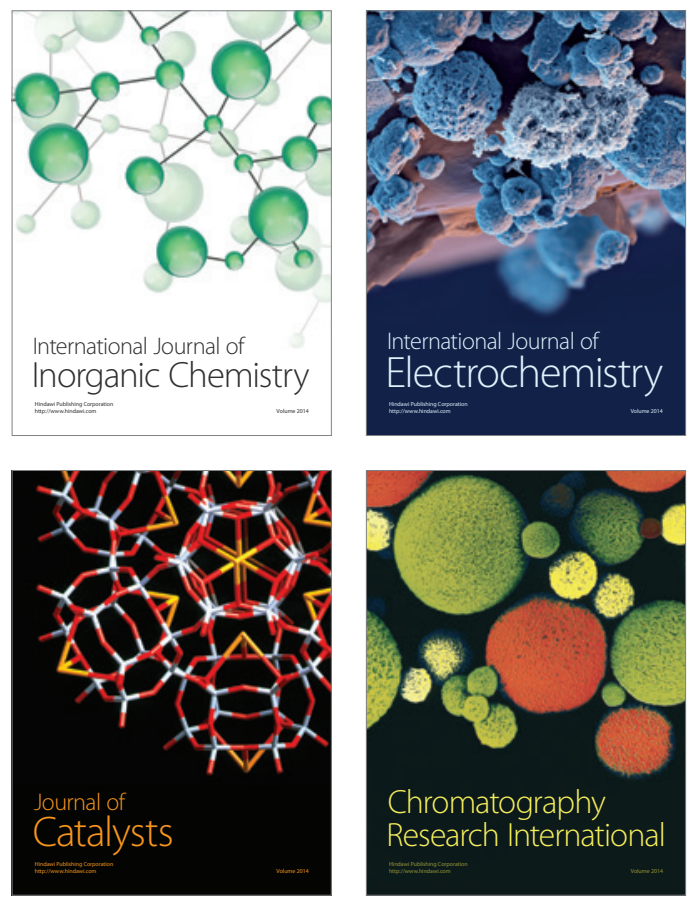
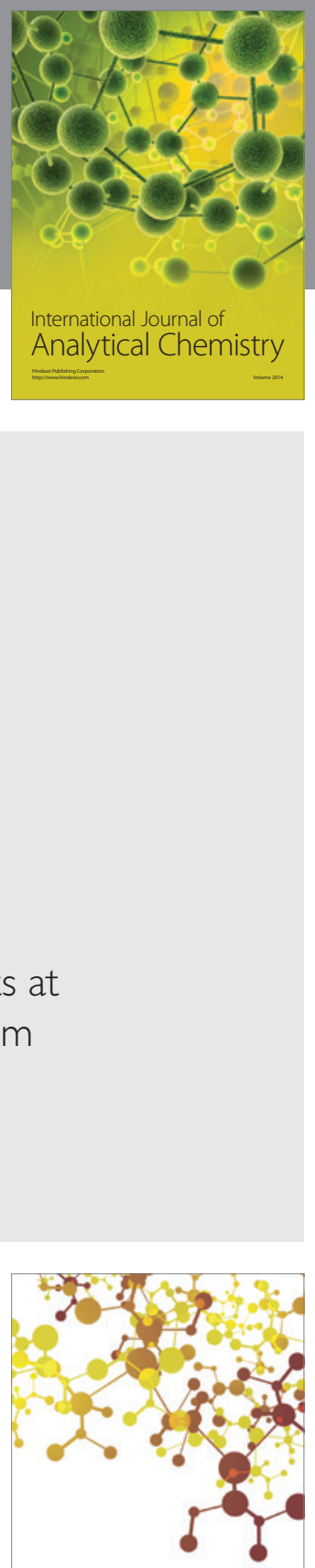

Journal of

Applied Chemistry
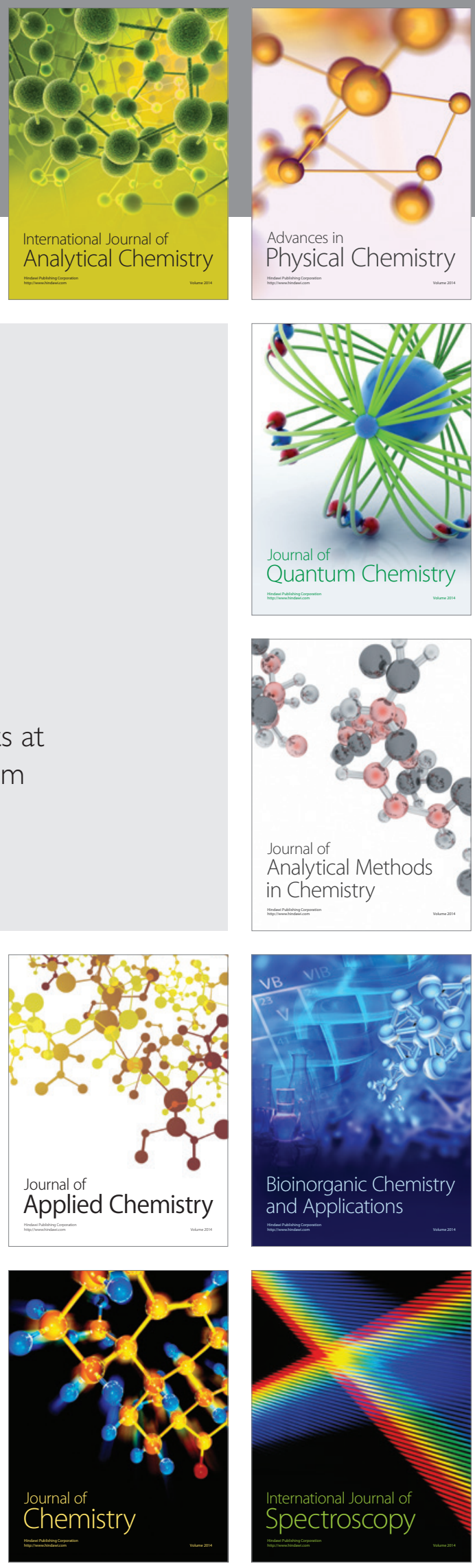